\title{
Effect of Sintering Temperature on the Microstructure and Electrical Characteristics of Low Clamping Voltage Zinc Oxide- Based Ceramic Varistor
}

\author{
J. O. Akinnifesi ${ }^{1} \&$ O. O. Akinwunmi ${ }^{1}$ \\ ${ }^{1}$ Department of Physics and Engineering Physics, Obafemi Awolowo University, Ile-Ife, Nigeria \\ Correspondence: J. O. Akinnifesi, Department of Physics and Engineering Physics, Obafemi Awolowo University, \\ Ile-Ife, Nigeria. E-mail: akinnifesi@yandex.com
}

Received: April 7, 2015 Accepted: April 14, 2015 Online Published: May 15, 2015

doi:10.5539/jmsr.v4n3p40 URL: http://dx.doi.org/10.5539/jmsr.v4n3p40

\begin{abstract}
Pelletized samples of polycrystalline zinc oxide ceramics doped with $2 \mathrm{~mol} \% \mathrm{MnO}_{2}$ and $3 \mathrm{~mol} \% \mathrm{PbO}$ were prepared by the conventional method of ceramic processing. The requisite composition was obtained by the direct mixing of constituent phases (DMCP) technique. Sintering was carried out at various temperatures ranging from $650^{\circ} \mathrm{C}$ to $850^{\circ} \mathrm{C}$. The effects of sintering on the non-linear characteristics of the doped ceramic samples were investigated. The threshold or breakdown voltages were found to decrease as sintering temperature increased.

Microstructural investigation revealed improved homogeneity and increased grain sizes with increasing sintering temperature. The random distribution of secondary phases also featured prominently. These findings were observed to correlate with the evolution of electrical characteristics while the sample sintered at $850^{\circ} \mathrm{C}$ exhibited the best electrical response suitable for varistor behaviour.
\end{abstract}

Keywords: $\mathrm{ZnO}$ varistor, sintering temperature, densification, microstructure, electrical characteristics.

\section{Introduction}

A number of studies have successfully proved that $\mathrm{n}$ - type doped zinc oxide ceramics are effective material for varistors or voltage- dependent resistors (VDR), using transition metal oxides as the dopant. The role of the individual dopants in forming potential barriers to electron flow has been reported (Clark, 1999; Haskell et al., 1999; Duran et al., 2003). Varistors have applications in the protection of electrical power transmission and electronic circuit devices against transient voltage surges (Gupta, 1990; Leach, 2005; Annas et al., 2007). Their current-voltage characteristics exhibit very high resistance at low voltages and low resistance at high voltages. The threshold voltage of transition to increased conduction, also known as clamping or breakdown voltage occur in a region of non-linearity (Matsuoka, 1991; Pillar et al., 2003). There have been reports in the literature on the basic physics of doped varistors (Levison et al., 1975; Entage, 1977), in addition to which a brief review will be pertinent here.

The microstructure of a varistor is made of thin intergranular phase separating $\mathrm{ZnO}$ grains which cause localized defects on the interface. These defects give rise to a schottky barrier which limits the current flow at low temperatures. When higher voltage is applied across the boundary layer, minority carriers are generated, thereby increasing conductivity significantly (Mahan et al., 1993; Pillat et al., 2003). The electronic potentials that build up at the grain boundaries arise from the charges trapped at the interface states (Fernandez- Hevia et al., 2004; Leach, 2005). Consequently, the equivalent circuit of the varistor can be represented as a parallel combination of resistors and capacitors, while the bulk varistor consists of several series and parallel combinations of micro-varistors (Kourdi et al., 1992). In this way, they are equivalent to back-to-back zener diodes, with greater current and energy handling capabilities (Peitado et al., 2007).

The mixing of two or more components to form a multicomponents system separated by distinct interfaces produce superior material properties. The behaviour of such system depends on the composition and temperature of processing and when the free energy of the system is minimum, the system remains stable (Vijaya and Rangarajan, 2003). The microstructure of the polycrystalline material largely depends on the number, size, shape and rate of formation of phases present (Barrett et al., 1973). A previous study of a ternary varistor system sintered above $800^{\circ} \mathrm{C}$ showed that liquid phase reactions produced functional microstructure, promoting the densification of the ceramics and the growth of $\mathrm{ZnO}$ grains (Leite et al., 1996). It has also been reported that mechano-chemical 
activation (MCA) of microstructure resulted from using the direct mixing of constituent phases (DMCP) technique with high sintering temperature. This was found to significantly reduce particles' sizes and their compactness, giving rise to more homogeneous samples with higher density and finer distribution of secondary phases (Bernik et al., 2008). This finding confirmed an earlier report by kutty (2000).

In our previous investigations (Akinnifesi et al., 2014) we studied the electrical properties of $\mathrm{Mn}^{2+}-\mathrm{Pb}^{2+}$ - doped $\mathrm{ZnO}$ varistors and found this to be considerably influenced by the microstructure. Onreabroy et al. (2006) has also reported that the non-linear coefficient depended primarily on the sintering temperature and significantly decreased at higher temperatures. Breakdown voltages had equally been found to decrease linearly as average size of $\mathrm{ZnO}$ grains increased (Hozer, 1994). Interestingly, variation in microstructure and electrical properties at different sintering temperatures has been reported (Xu et al., 2009; Nahm, 2006) while homogeneity and development of interfaces have been related to sintering (Leach et al., 2000; Bernik et al., 2001). Significantly, the evolution of particle size and distribution during processing is temperature-sensitive. Consequently, the breakdown voltages can be varied by changing the grain size under sintering condition (Lee et al., 2007).

The objective of this work is therefore to investigate the effect of varying sintering temperature on the microstructure and electrical characteristics of bulk specimen of $\mathrm{Mn}^{2+}-\mathrm{Pb}^{2+}$ - doped zinc oxide ceramics. This is carried out by the conventional means of electron microscopy and X-ray diffraction techniques, as well as current-voltage characterization.

\section{Experimental Procedure}

\subsection{Sample Preparation:}

Reagent grade (Sigma Aldrich) $\mathrm{ZnO}$ powder of $99.9 \%$ purity and mean particle size $0.28 \mu m$ were doped with requisite amounts of $\mathrm{MnO}_{2}$ and $\mathrm{PbO}$ powders, by direct mixing of constituent phase procedure (DMCP). This method allows the preparation of bulk-type varistors with precisely defined components. Each phase is prepared separately and the final varistor is formed by sintering the powder mixture of constituent phases (Brankovic et al., 2007). Mixing was thoroughly done in a ceramic mortar for considerable homogeneity. The mixture was then entirely scooped into the mould and pelletized with Caver Hydraulic unit with a load of 7.49MPa for about 4 minutes to enhance effective compression. The resulting pellets were disk-shaped with about $2.00 \mathrm{~mm}$ in thickness and $10.0 \mathrm{~mm}$ in diameter. The thickness/diameter measurements were averaged, with no substantial deviation found. The composition was $95 \% \mathrm{ZnO}$ of $95 \mathrm{~mol} \% \mathrm{ZnO}$ with $2 \mathrm{~mol} \% \mathrm{MnO}_{2}$ and $3 \mathrm{~mol} \% \mathrm{PbO}$. Specimens of these pellets were sintered at different temperatures varying from $650^{\circ} \mathrm{C}$ to $850^{\circ} \mathrm{C}$ for about 6 hours in each case. Each specimen was inserted in quartz-tube before placing in the preheated oven, to ensure there was no reaction between the furnace interior and samples, thereby avoiding any contamination. It was then inserted at the preset temperature at a heating rate of $5^{\circ} \mathrm{C} / \mathrm{min}$ and subsequently oven-cooled to about $280^{\circ} \mathrm{C}$. It was finally removed outside the oven to cool to room temperature. As the cooling to room temperature was gradual, no disc bending resulted.

\subsection{Density, $\rho$ Determination}

The density of the sintered pellets were determined firstly by precise geometrical measurements of their dimension using the micrometer screw gauge. This was followed by a precise weighing of the pellet with an electronic balance of sensitivity $10^{-4} \mathrm{~g}$. The mass to volume ratio of each of the samples prepared at different sintering temperatures was then evaluated to obtain the densities

\subsection{Measurements of Microstructure:}

To observe the microstructure of the sintered doped-ZnO ceramic samples, the fractured surface was coated with gold for examination under a Scanning Electron Microscope. The micrographs were produced by the CARL-ZEISS machine, model EVOMA10. Average grain size was determined by the linear intercept method. The crystalline phases were identified by X-ray Diffractometry. For this, a Radicon MD 10 diffractometer making use of $\mathrm{CuK} \alpha$ radiation at $1.5418 \mathrm{~A}^{\circ}$, in the detection range between $16^{\circ}$ and $72^{\circ}$ was employed.

\subsection{Measurement of Electric Field-Current Density (E-J) Characteristics}

The DC current-voltage characteristics of the sintered samples were measured by coating silver paste onto the opposite faces of the samples. The silver electrodes of $5 \mathrm{~mm}$ in radius were formed by heating at $500^{\circ} \mathrm{C}$ for about 10 minutes, to establish ohmic contact. The current and voltages were obtained with a Keitheley electrometer, model $2636 \mathrm{~A}$ and the values were expressed as current densities (in terms of the unit length of the varistor thickness respectively). Hence the breakdown voltages of the samples were obtained for different sintering temperatures. 


\section{Results and Discussion}

\subsection{Densification}

The variation of the density of the varistor samples sintered at different temperatures is shown in Figure 1. An initial increase in densification with increasing temperature is revealed. This is followed by a drop in value at a temperature of $800^{\circ} \mathrm{C}$. The initial increase may have arisen from the annihilation of probable voids in the microstructure, as well as from the formation of new phases and growth of $\mathrm{ZnO}$ grains (Han et al., 1999; Han et al., 2000). The drop is also indicative of the onset of significant loss in dopant materials at higher sintering temperature. This loss is manifested by the decrease in XRD peak intensity of $\mathrm{PbO}_{2}$ from 0.75 at $800^{\circ} \mathrm{C}$ to 0.35 at $850^{\circ} \mathrm{C}$ and that of $\mathrm{MnO}_{2}$ from 0.60 to 0.10 over the same range of temperature increase. This could serve as a guide to the choice of temperature of sintering. Densification at higher sintering temperatures can be improved by increasing the Mn doping level as this has been found to promote grain growth in the final stages of sintering (Han et al., 2002).

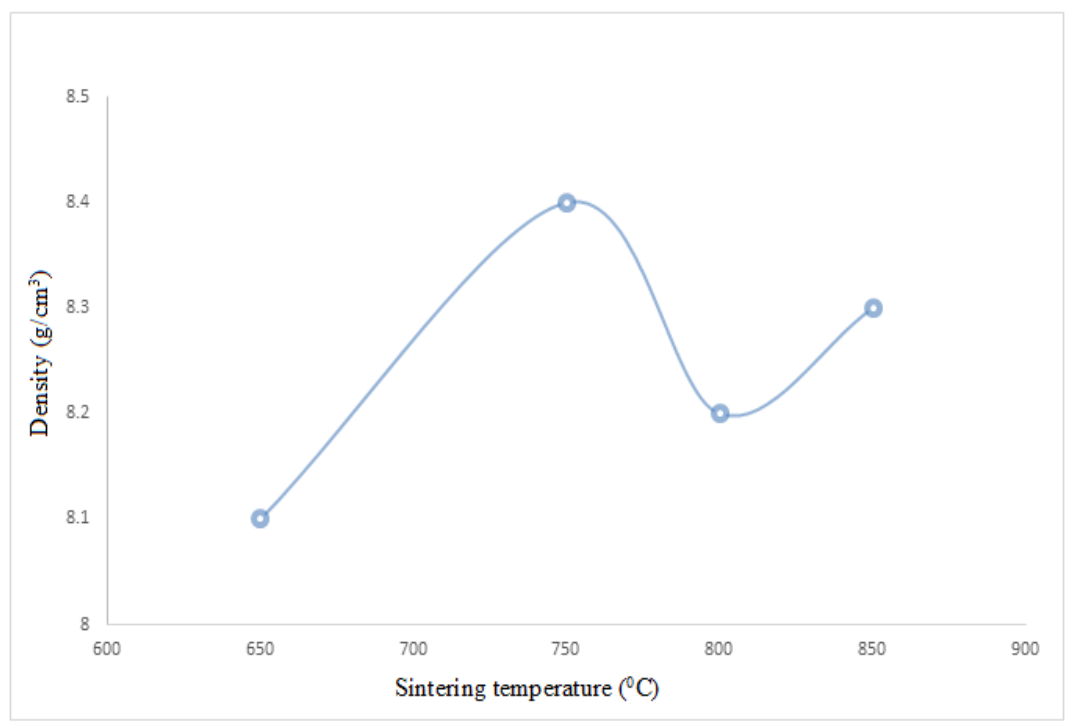

Figure 1. Variation of densification with sintering temperature

\subsection{Microstructural Studies}

Figure 2(a-d) show the scanning electron micrographs of the sintered doped $\mathrm{ZnO}$ ceramic samples at different temperatures of sintering. These basically consist of different phases with $\mathrm{ZnO}$ as the main phase. From the appearance of the phase distributions the microstructures seem identical, though with trends of improved matrix homogeneities with increasing sintering temperature. Better homogeneities have been reported to confer better varistor characteristics (Bernik et al., 2008). The variation of average grain size with sintering temperature is shown in Figure 3, in which the grain sizes increase with the sintering temperature. The emergence of the different phases with the different sintering temperatures is revealed by the x-ray diffraction spectra of the doped ceramic samples shown in Figure 4(a-d). More phases are observed to form with increasing sintering temperature, thus contributing to the creation of interface barriers to electrical conduction. The improvement in varistor behaviour would consequently be enhanced. 


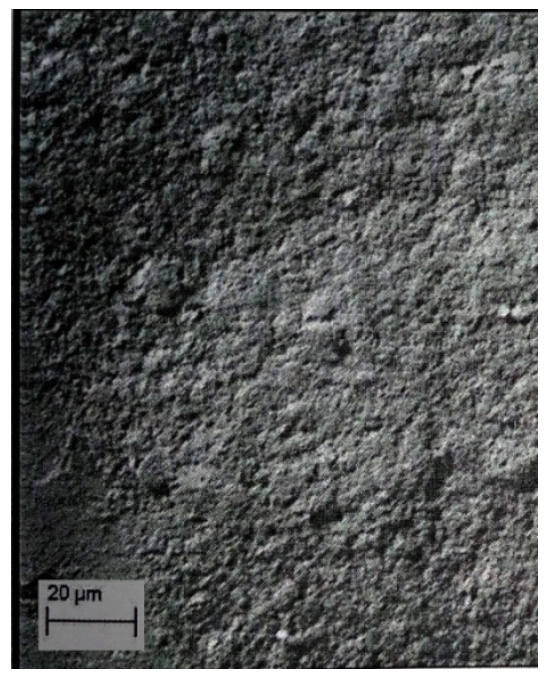

a

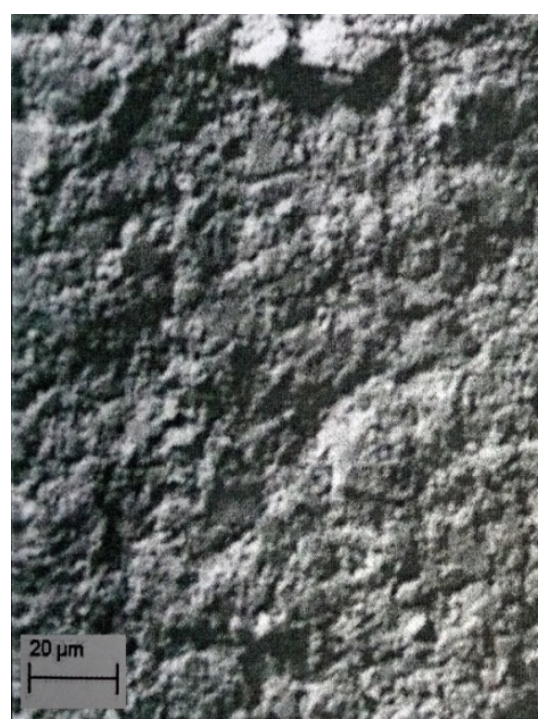

c

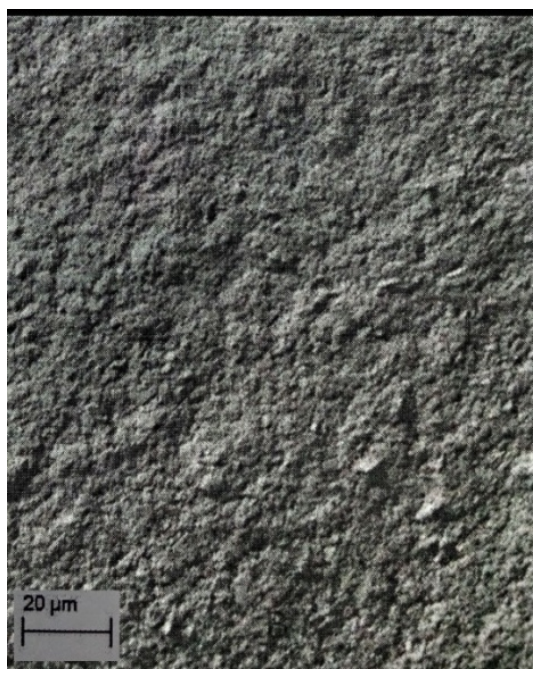

$\mathrm{b}$

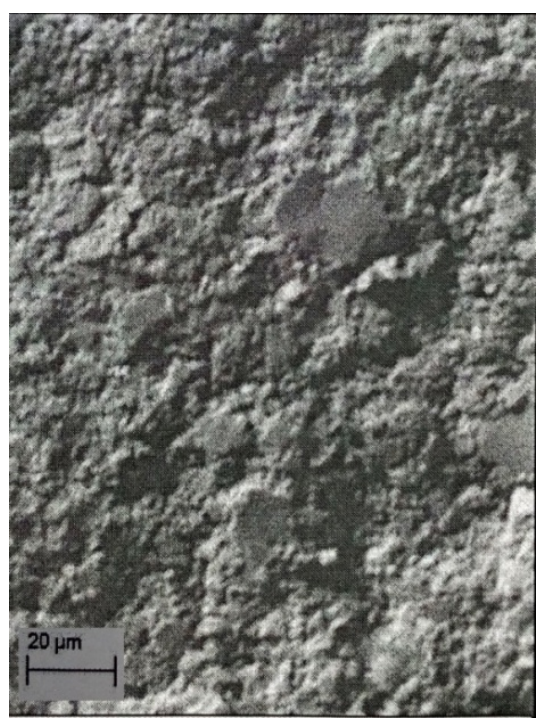

d

Figure 2. SEM Micrographs of samples sintered at (a) $650^{\circ} \mathrm{C}$, (b) $750^{\circ} \mathrm{C}$, (c) $800^{\circ} \mathrm{C}$ and (d) $850^{\circ} \mathrm{C}$

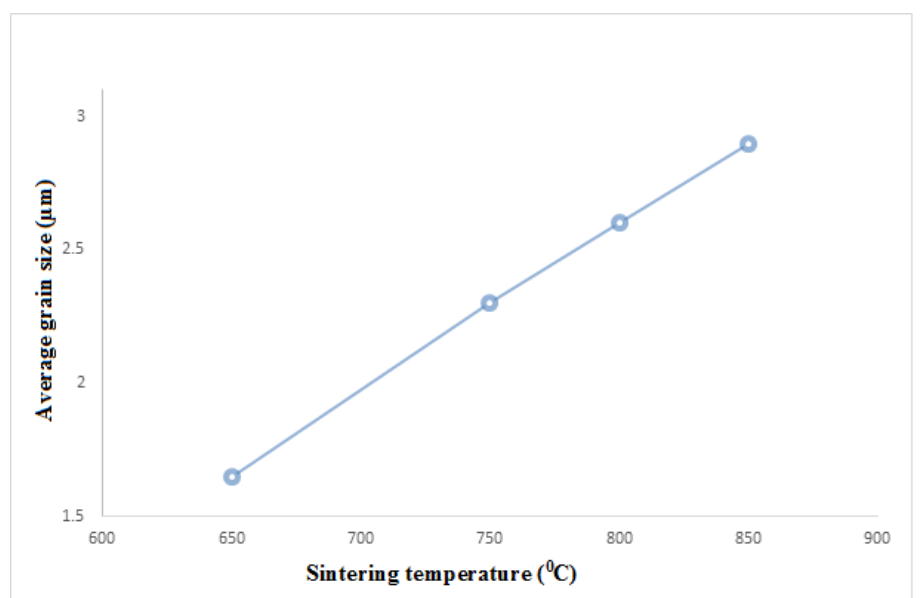

Figure 3. Variation of average grain size with sintering temperature 


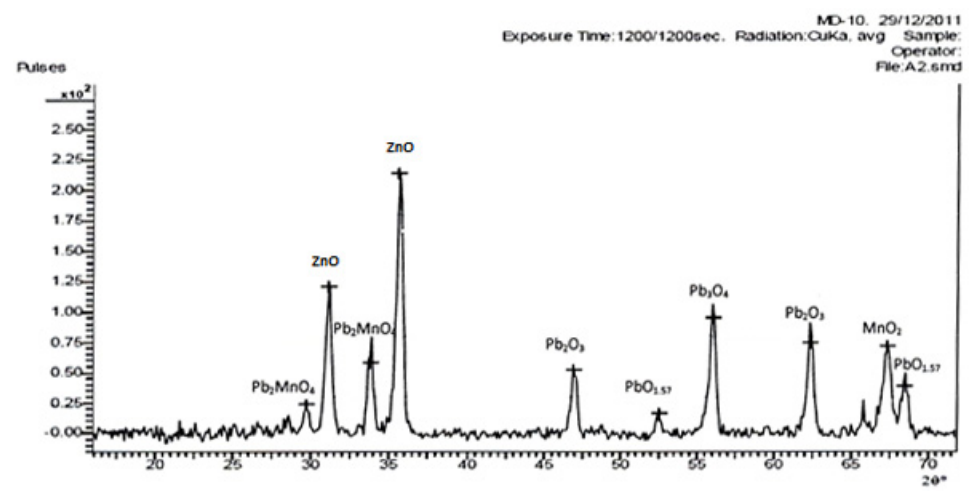

(a)

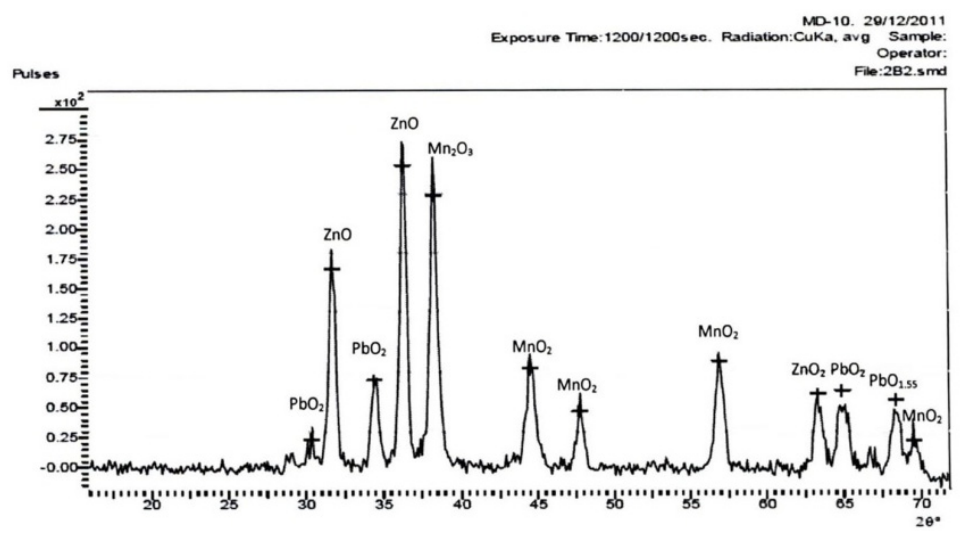

(b)

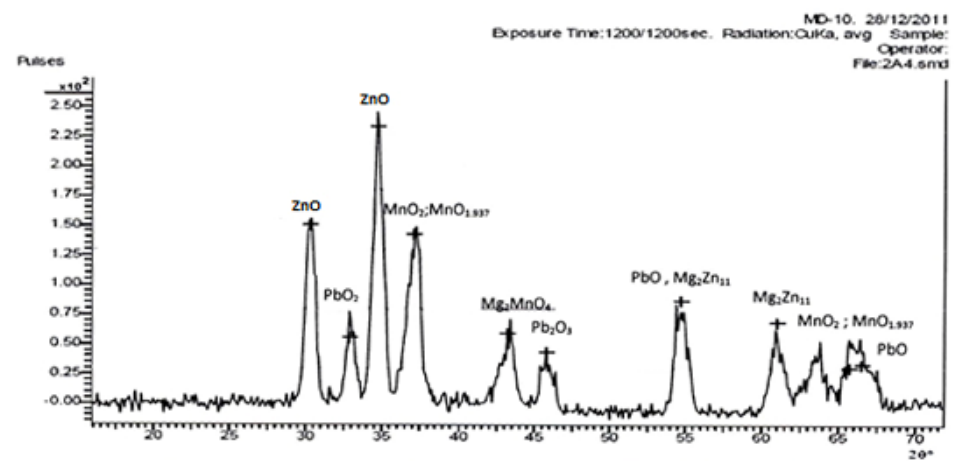

(c)

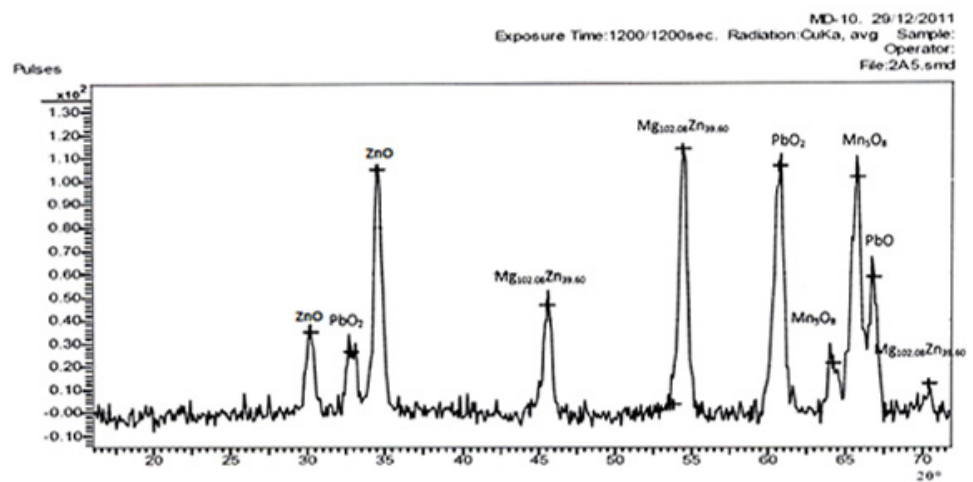

(d)

Figure 4. XRD Spectra of the sintered samples at (a) $650^{\circ} \mathrm{C}$, (b) $750^{\circ} \mathrm{C}$, (c) $800^{\circ} \mathrm{C}$ and (d) $850^{\circ} \mathrm{C}$. 


\subsection{Electrical Characteristics}

The properties of varistors are best highlighted by the electrical characteristics which result from the fabrication processes, particularly sintering. Figure 5 shows the current-voltage characteristics of the doped $\mathrm{ZnO}$ ceramic samples sintered at the various temperatures. These exhibit a sharp transition in the electric field from low current zones to non-linear region of higher currents. The associated threshold or breakdown voltages $\mathrm{V}_{\mathrm{b}}$, vary with the sintering temperatures as shown in Figure 6 , where $\mathrm{V}_{\mathrm{b}}$ decreases with increasing sintering temperatures. This variation is traceable, on one hand to the formation and consequent growth of secondary phases at the different temperatures. According to Zhang et al. (2005), the growth of secondary phases involves the dissolution of cations which makes the interphase junctions more electrically active. On the other hand, the increased average grain sizes would lead to increased conductivity and a consequent reduction in the breakdown voltage. This phenomenon was previously observed by Cheng et al. (2007). Hence, the formation of several polymorph phases and increase in grain sizes in the sample sintered at $850^{\circ} \mathrm{C}$ explains the occurrence of a minimum breakdown voltage at this temperature. However, it is evident from Figure 5 that the increase in breakdown voltage is accompanied by increased leakage currents. This is indicative of a deterioration tendency in the varistor microstructure. Nahm (2004), Leach et al. (2006) and Nahm (2007) have all reported a lowering of the barrier height and poorer non-linearity in the electrical response of excessively sintered varistors.

In the overall analysis, considering the knee of the non-linearity in electrical response and other important parameters, the best varistor behavior is exhibited by the sample sintered at $850^{\circ} \mathrm{C}$.

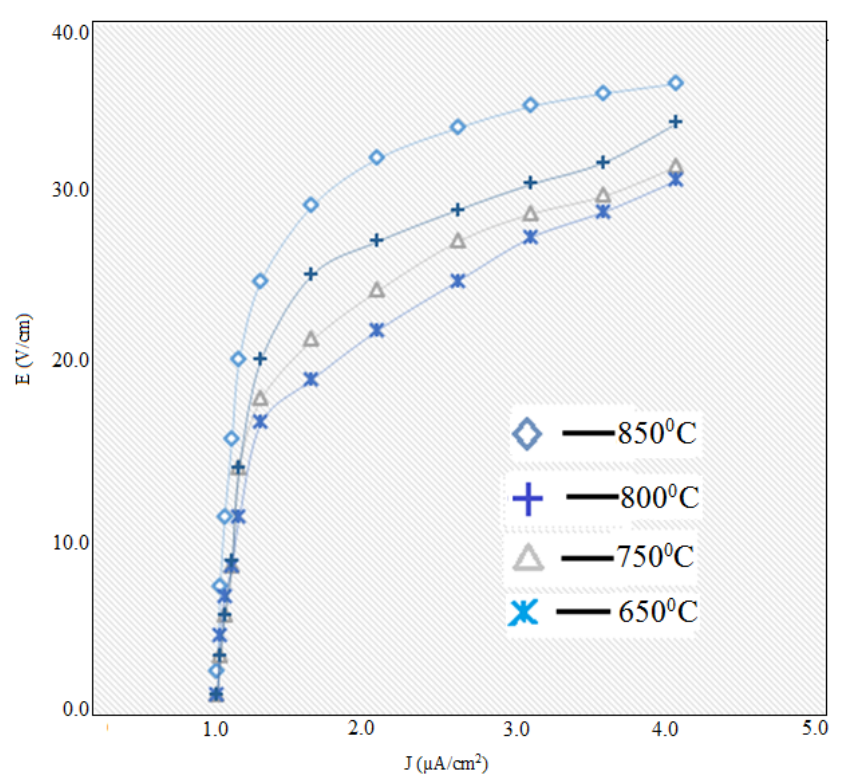

Figure 5. Current- voltage (J-E) characteristics of the sintered samples

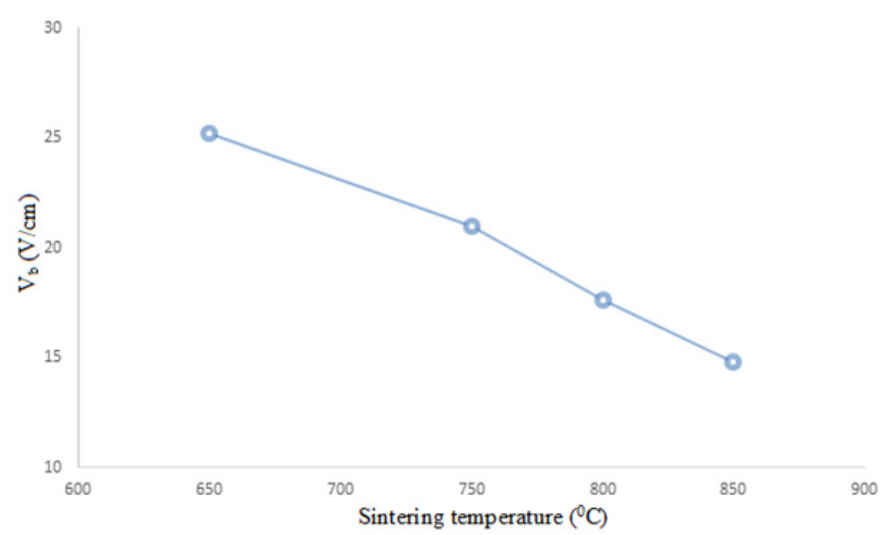

Figure 6. Variation of breakdown voltage, $\mathrm{V}_{\mathrm{b}}$ with sintering temperature 


\section{Conclusion}

The influence of sintering temperature on the microstructure and electrical response of $\mathrm{MnO}_{2}-\mathrm{PbO}$ - doped $\mathrm{ZnO}$ varistor ceramics were investigated between $650^{\circ} \mathrm{C}$ and $850^{\circ} \mathrm{C}$. The samples exhibited initial densification with increased sintering temperature.

This was followed by a reduction in densification at $800^{\circ} \mathrm{C}$ and a subsequent improvement at a sintering temperature of $850^{\circ} \mathrm{C}$. SEM studies showed improved homogeneity with increasing temperature. The grain sizes also increased accordingly while XRD spectra revealed the formation of secondary polymorphic phases. The electrical characteristics exhibited sharp transitions from ohmic to non-ohmic response and the associated breakdown voltage decreased with increased sintering temperature.

The improvement in electrical response with increased sintering temperature was attributed to the improved microstructural homogeneities as indicated by more uniform phase distribution and narrower grain boundaries. The best characteristics found suitable for varistor behaviour was exhibited by the sample sintered at $850^{\circ} \mathrm{C}$ for 6 hours. However, the duration of sintering may have been crucial to the microstructural evolutions of the ZnO-based ceramic varistor samples. As the microstructural findings correlated with the electrical characteristics, it follows that breakdown voltages can be significantly controlled by means of the sintering process.

\section{Acknowledgements}

The authors would like to thank the XRD staff of Center for Energy Research and Development (CERD), Obafemi Awolowo University, Ile-Ife; Nigeria. We are also grateful to the SEM staff of Sheda Science and Technology Complex (SHESTCO), Abuja Nigeria; and to Dr Ilori of the Electrical and Electronics Engineering Department, Obafemi Awolowo University, Ile-Ife for their technical supports.

\section{References}

Akinnifesi, J. O., Erinfolani, F. B., \& Akinwunmi, O. O. (2014). Influence of microstructure on the non- ohmic behavior of zinc oxide varistor ceramics prepared by direct mixing of constituent phases. Ife Journal of Science, 16, 91- 98 .

Anas, S., Mangalaraja, R. V., Poothayal, M., Shukla, S. K., \& Ananthakumar, S. (2007). Direct synthesis of varistor-grade doped nanocrystalline $\mathrm{ZnO}$ and its densification through a step-sintering technique. Acta Materialia, 55(17), 5792-5801. http://dx.doi.org/10.1016/j.actamat.2007.06.047

Barett, C., Nix, W., \& Tetelman, A. (1973). The principles of engineering materials. New Jersey: Prentice Hall.

Bernik, S., Brankovic, G., Rustja, S., Zunic, M., \& Pollogar, Z. (2008). Compositional aspects of ZnO-based varistor ceramics prepared by direct mixing of the constituent phases and high energy milling. Ceramics international, 34,1495-1502. http://dx.doi.org/10.1016/j.ceramint.2007.04.003

Bernik, S., Marcek, S., \& Bui, A. (2001). Microstructural and electrical characteristics of $\mathrm{V}_{2} \mathrm{O}_{3}$ - doped $\mathrm{ZnO}-$ $\mathrm{Bi}_{2} \mathrm{O}_{3}$ - based varistor ceramics. Journal of the European Ceramic Society, 21, 1875-1878. http://dx.doi.org/ 10.1016/S0955-2219(01)00134-0

Brankovic, Z., Brankovic, G., Bernik, S., \& Zunic, M (2007). ZnO varistors with reduced amount of additives prepared by direct mixing of constituent phases. Journal of the European Ceramic Society, 27, 1101-1104. http://dx.doi.org/10.1016/j.jeurceramsoc.2006.05.040

Cheng, P. F., Li, S. T., \& Alim, M. A. (2007). Soft core behaviour in $\mathrm{ZnO}-\mathrm{Bi}_{2} \mathrm{O}_{3}$ based varistors containing oxides of Ce and Gd. Physica Status Solidi A-Applications and materials science, 204, 887-899. http://dx.doi.org/ 10.1002/pssa.200622180

Clarke, D. R. (1999). Varistor Ceramic Journal of the American Ceramic Society, 82, 2106-2110. http://dx.doi.org/10.1111/j.1151-2916.1999.tb01793.x

Duran, P., Tarjaj, J., \& Moure, C. (2003). Fully dense, fine-grained doped zinc oxide varistors with improved non-linear properties by thermal processing optimization. Journal of the American Ceramic Society, 86, 1326-1329. http://dx.doi.org/10.1111/j.1151-2916.2003.tb03470.x

Entage, R. (1977). Physics of zinc oxide varistors. J. Appl. Phys., 48, 4372-4384. http://dx.doi.org/10.1063/ 1.323391

Fernandez-Hevia, D., Peitado, M., De Frustos, J., Caballero, A., \& Fernandez, J. (2004). Wide range dielectric spectroscopy of $\mathrm{ZnO}$ - based varistors as a function of sintering time. Journal of the European Ceramic Society, 24, 1205-1208. http://dx.doi.org/10.1016/S0955-2219(03)00411-4 
Gupta, T. K. (1990). Application of zinc oxide varistors. J. Am. Ceram. Soc., 7, 1814-1840. http://dx.doi.org/ 10.1111/j.1151-2916.1990.tb05232.x

Han, J., Mantas, P. Q., \& Senos, A. M. R. (2000). Grain growth in Mn- doped ZnO ceramics. J. Eur. Ceram Soc., 20, 2753-2758. http://dx.doi.org/10.1016/S0955-2219(00)00220-X

Han, J., Senos, A. M. R., \& Mantas, P. Q. (1999). Non - isothermal sintering of Mn-doped ZnO ceramics. J. Eur. Cera Soc., 19, 1003-1006. http://dx.doi.org/10.1016/S0955-2219(98)00362-8

Han, J., Senos, A. M. R., \& Mantas, P. Q. (2002) : Vaistor behavior of Mn-doped ZnO ceramics. J. Eur. Ceram Soc., 20, 1653-1660. http://dx.doi.org/10.1016/S0955-2219(01)00484-8

Haskell, B. A., Souri, S. J., \& Helfand, M. A. (1999). Varistor behaviour at grain- boundaries in ZnO. J. Am. Ceram. Soc., 82, 2106-2110. http://dx.doi.org/10.1111/j.1151-2916.1999.tb02048.x

Hozer, L. (1994). Metal oxide varistors, semiconductor ceramics: grain boundary effects (pp. 44-109). Warszawa: Polish Scientific Publishers.

Kourdi, M., Bui, A., louibierre, A., \& Khedim, A. (1992). Behaviour of metal oxide based varistors subjected to partial discharge in air. J. Phys. D. Appl. Phys., 25, 548. http://dx.doi.org/10.1109/ICSD.1992.224942

Kutty, T. (2000). Effect of sintering temperature on microstructure of ceramics. Journal of Materials Chemistry and Physics, 63, 218.

Leach C., Ling, Z., \& Freer, R. (2000). The effect of sintering temperature variation on the development of electrically active interfaces in zinc oxide based varistors. Journal of the European Ceramic Society, 20, 2759 http://dx.doi.org/10.1016/S0955-2219(00)00223-5

Leach, C. (2005). Grain boundary structures in zinc oxide varistors. Acta Materiala, 53, 237-245. http://dx.doi.org/10.1016/j.actamat.2004.07.006

Lee, W. S, Chen, W. T., Lee, Y. C., Yang, T., Su, C. Y., \& Hu, C. L. (2007). Influence of sintering on microstructures and electrical properties of $\mathrm{ZnO}$ - based multilayer varistors. Ceramics International, 33, 1001-1005. http://dx.doi.org/10.1016/j.ceramint.2006.02.017

Leite, E. R., Nobre, M. A. L., Longo, E., \& vareta, J. A. (1996). Microstructural development of ZnO Varistors during reactive liquid phase sintering . J. mater. Sci., 31, 5391-5398 http://dx.doi.org/10.1007/BF01159308

Levinson, L. M., \& Philipp, H. R. (1975). Physics of metal oxide varistors. J. Appl. Phys., 46, 1332-1341. http://dx.doi.org/10.1063/1.321701

Mahan, G., Levinson, M., \& Philipp, H. (1993). Theory of conduction in ZnO varistors. J.Appl. Phys., 54, 2799-2812.

Matsuoka, M. (1991). Non-ohmic properties of zinc oxide ceramics. Jpn. J. Appl. Phys., 10, 736- 746. http://dx.doi.org/10.1143/JJAP.10.736

$\mathrm{Nahm}, \mathrm{C}$. (2006). Effects of sintering temperature on microstructure and electrical properties of $\mathrm{Zn}, \mathrm{Pr}, \mathrm{Co}, \mathrm{La}$ oxide - based varistors. Mater. Lett., 60, 3394. http://dx.doi.org/10.1007/s10853-005-2185-3

Nahm, C. (2007). The effect of sintering temperature on electrical properties and accelerated aging behaviour of PCCL - doped $\mathrm{ZnO}$ varistors. Materials Science and Engineering. B., 136, 34-139. http://dx.doi.org/10. 1016/j.mseb.2006.09.010

Nahm, C. W. (2004). Effect of sintering time on varistors properties of $\mathrm{Dy}_{2} \mathrm{O} 3$ - doped $\mathrm{ZnO}-\mathrm{Pr}_{6} \mathrm{O}_{11}-$ based ceramics. Materials letters, 58, 3297-3300. http://dx.doi.org/10.1016/j.matlet.2004.06.020

Onreabroy, W., Sirikulrat, N., Brown, A. P., Hammond, C., \& Milne, S. J. (2006). properties and intergranular phase analysis of a $\mathrm{ZnO}-\mathrm{CoO}-\mathrm{Bi}_{2} \mathrm{O}_{3}$ varistors. Solid State Ionics, 177, 411-420. http://dx.doi.org/10.1016/ j.ssi.2005.10.032

Peitado, M., Fernandez, J., \& Caballero, A. (2007). Varistor based in the $\mathrm{ZnO}-\mathrm{Bi}_{2} \mathrm{O}_{3}$ system -microstructure control and properties. Journal of the European Ceramic Society, 27, 3867-3872. http://dx.doi.org/10.1016/ j.jeurceramsoc.2007.02.046

Pillar, S., Kelly, J., Mccormack, D., O’brien, P., \& Ramesh, R. (2003). The effect of processing conditions on varistors prepared from nanocrystalline ZnO. Journal of Materials Chemistry, 13, 2586-2590.

Vijaya, M., \& Rangarajan, G. (2003). Materials Science (pp. 122-123). New Delhi: McGraw Hill Co. 


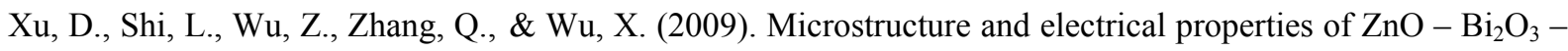
based varistor ceramic by different sintering process. Journal of the European Ceramic Society, 29, 1789-1794. http://dx.doi.org/10.1016/j.jeurceramsoc.2008.10.020

Zhang, J., Cao, S., Zhang, R., Yu, L., \& Jing, C. (2005). Effect of fabrication conditions on the I-V properties for $\mathrm{ZnO}$ varistors with high concentration of additives by sol - gel technique. Current Applied Physics, 5, 381-386. http://dx.doi.org/10.1016/j.cap.2004.03.004

\section{Copyrights}

Copyright for this article is retained by the author(s), with first publication rights granted to the journal.

This is an open-access article distributed under the terms and conditions of the Creative Commons Attribution license (http://creativecommons.org/licenses/by/3.0/). 